\title{
Meta-analysis of the association between sodium-glucose cotransporter 2 inhibitors and risk of skin cancer among patients with type 2 diabetes
}

Short title: SGLT2 inhibitors and Skin Cancer

Huilin Tang $\mathrm{MSc}^{1}$, Keming Yang $\mathrm{MD}^{1}$, Yiqing Song MD, $\mathrm{ScD}^{1}$, Jiali Han $\mathrm{PhD}^{1,2}$

${ }^{1}$ Department of Epidemiology, Richard M. Fairbanks School of Public Health, Indiana

University, Indianapolis, Indiana, USA

${ }^{2}$ Melvin and Bren Simon Cancer Center, Indiana University, Indianapolis, Indiana, USA

\section{Corresponding author:}

Jiali Han, $\mathrm{PhD}$

Department of Epidemiology,

Richard M. Fairbanks School of Public Health, Indiana University, 1050 Wishard Blvd, Indianapolis, Indiana, 46202, USA

Phone: 317-278-0370; Fax: 317-274-3433

Email: ஹialhan@iu.edu

Brief Report

Word count: 1464

Number of tables/figures: $1 / 1$

This is the author's manuscript of the article published in final edited form as:

Tang, H., Yang, K., Song, Y., \& Han, J. (2018). Meta-analysis of the association between sodium-glucose cotransporter 2 inhibitors and risk of skin cancer among patients with type 2 diabetes. Diabetes, Obesity and Metabolism, 0(ja). https://doi.org/10.1111/dom.13474 


\section{ABSTRACT}

A slight increase in melanoma risk was observed among sodium-glucose cotransporter 2 (SGLT2) inhibitor users in the regular reports. However, the association remains uncertain. To address this issue, we performed a systematic search of electronic databases up to May 2, 2018 and a meta-analysis of 21 randomized controlled trials (RCTs) involving 20,816 patients. We did not find a significant increase in risk of melanoma among SGLT2 inhibitor users (Peto odds ratio [OR], 2.17; 95\% confidence interval $[\mathrm{Cl}], 0.80$ to $5.89 ; \mathrm{I}^{2}, 0 \%$ ). Similar results were observed in the subgroup analyses according to type of SGLT2 inhibitor, type of control, ages of patients, race/ethnicity, and trial durations. For non-melanoma skin cancer risk, no significant difference was observed when all trials were combined (Peto OR, $0.70 ; 95 \% \mathrm{Cl}, 0.47$ to $\left.1.07 ; I^{2}, 0 \%\right)$ while a significantly decreased risk was observed among trials with duration $<52$ weeks (Peto OR, $0.12 ; 95 \% \mathrm{Cl}, 0.02$ to $0.59 ; \mathrm{I}^{2}, 0 \%$ ). No evidence of publication was detected in the analyses. Current evidence from RCTs did not support a significantly increased risk of skin cancer associated with SGLT2 inhibitors. 


\section{INTRODUCTION}

Sodium glucose cotransporter 2 (SGLT2) inhibitors are a novel class of antidiabetic drugs for the treatment of type 2 diabetes (T2D). ${ }^{1}$ They lower blood glucose by inhibiting the reabsorption of glucose in the kidney. Given their additional benefits to the cardiovascular and renal systems, ${ }^{2-5}$ more and more patients will be prescribed this class of medication. However, some evidence has indicated that SGLT2 inhibitors may lead to serious adverse events (e.g., diabetic ketoacidosis and below-knee lower extremity amputation) ${ }^{6,7}$ Furthermore, a slightly elevated risk of melanoma associated with empagliflozin use raises regulatory concerns.$^{8,9}$ Given the rarity of melanoma cases in most randomized controlled trials (RCTs), such safety issues are difficult to be addressed based on any individual short-term trial. Therefore, we conducted this meta-analysis of RCTs to comprehensively synthesize the evidence and maximize statistical power to detect any association between SGLT2 inhibitors and risk of skin cancer, including melanoma and non-melanoma skin cancer (NMSC) among patients with T2D.

\section{METHODS}

\subsection{Search strategy and study selection}

PubMed, Embase, Cochrane Central Register of Controlled Trials (CENTRAL), and 
ClinicalTrials.gov were searched from inception to May 2, 2018 using relevant search terms without language restrictions (Table S1). The reference lists of included studies, review articles, and meta-analyses were checked to find additional eligible trials.

We included eligible trials that fulfilled the following criteria: 1) published and unpublished RCTs; 2) adults patients with T2D; 3) comparison of SGLT2 inhibitors with placebo or other antidiabetic drugs; 4) trials with follow-up for at least 12 weeks; 5) reported the outcomes of melanoma and NMSC (basal cell carcinoma and squamous cell carcinoma).

\subsection{Data extraction and risk of bias assessment}

Two reviewers independently selected the potential trials, extracted data, and assessed the risk of bias of included trials. Any disagreements were resolved by consensus. We extracted the baseline demographic data, type of SGLT2 inhibitor, type of control, background therapy, trial duration, and outcomes of interest. The data from the trial with longest follow-up period were used in case of various follow-up periods reported. For a three-arm trial comparing $A+B$ vs. A vs. B, only two arms (A vs. B) were included in the meta-analysis. If skin cancer events were not reported in publication, these data were extracted from Clinicaltrials.gov website (www.clinicaltrials.gov). The risk of bias for each trial was assessed according to the Cochrane Collaboration tool for assessing risk of bias. $^{10}$

\subsection{Statistical analysis}


Due to rare incidence of skin cancer events, we used Peto odds ratio (OR) with 95\% confidence interval $(\mathrm{Cl})$ to pool the data. ${ }^{11} \mathrm{~A} /{ }^{2}$ statistic was performed to test between-study heterogeneity, with a $l^{2}$ value of $25 \%-50 \%, 50 \%-75 \%$, and $>75 \%$ corresponding to low, moderate, and high, respectively while a value of $I^{2}<25 \%$ represented no significant heterogenity. ${ }^{12}$ To explore the source of heterogeneity, subgroup analyses were carried out based on type of SGLT2 inhibitor (empagliflozin versus canagliflozin versus dapagliflozin versus ertugliflozin versus ipragliflozin), type of control (placebo versus other active antidiabetic drugs), race/ethnicity (white versus Asian), mean or median age of patients ( $<60$ years versus $\geq 60$ years), and trial duration( $<52$ weeks versus $\geq 52$ weeks). To test interactions by these prespecified factors, $p$ values for interactions were provided based on Cochran's $Q$ test for assessing differences between the subgroups stratified by each factor, respectively. Further, meta-regression including each stratified factor as an independent variable (on a dichotomous scale) was also performed to investigate if the heterogeneity changed significantly between the subgroups stratified by that factor mentioned above. ${ }^{13}$ Potential publication bias was assessed using both funnel plot and egger's test. All statistical analyses were performed with STATA version 14 (College station, TX). A p value $<0.05$ was considered as statistically significant.

\section{RESULTS}

This article is protected by copyright. All rights reserved. 
Among the 3,628 citations retrieved from the above-mentioned electronic databases, 21 eligible RCTs involving 20,816 patients (median: 690; range: 332 to 7,020 individuals) were included in this meta-analysis (Figure S1). The characteristics and risk of bias of the studies included were presented in Table $\mathbf{S} 2$ and Figure $\mathbf{S} 2$ respectively. The incidence of skin cancers was reported in only three articles and the others were extracted from www.clinicaltrials.gov.

There were 15 incident cases of melanoma in the SGLT2 inhibitor group and 3 in the control group during follow-up (median: 52 weeks; range: 12 to 160 weeks). The event rate in the SGLT2 inhibitor group (0.1\%) was higher than in the control group $(0.04 \%)$, yielding a Peto OR of 2.17 ( $95 \% \mathrm{Cl}, 0.80$ to 5.89$)$ (Figure 1). The subgroup analyses according to type of SGLT2 inhibitor, type of control, mean or median ages of patients, race/ethnicity, and trial durations did not identify any significant associations (Table 1).

In terms of NMSC risk, no significant association with SGLT2 inhibitors was observed when all trials were combined (Peto OR, $0.70 ; 95 \% \mathrm{Cl}, 0.47$ to 1.07 ), with event rates of $0.4 \%$ in the SGLT2 inhibitor group and $0.6 \%$ in the control group (Figure 1). When exploring the source of heterogeneity, the risk did not differ by the type of SGLT2 inhibitor, type of control, mean or median ages of patients (Table 1). However, a significantly decreased risk of NMSC associated with SGLT2 inhibitors was observed among trials with duration $<52$ weeks (Peto OR, $0.12 ; 95 \% \mathrm{Cl}, 0.02$ to 0.59 ), but not among those $\geq 52$ weeks (Peto OR, $0.80 ; 95 \% \mathrm{Cl}, 0.52$ to 1.23 ) ( $p$ for interaction $<0.05$ ) 


\section{(Table 1).}

We observed zero, low, and moderate degree of between-study heterogeneity in the analyses, with $l^{2}$ ranging from $0 \%$ to $56.4 \%$ (Table 1 ). There was no evidence of publication bias based on Egger's test ( $p=0.83$ for melanoma, and $p=0.54$ for NMSC) and funnel plot (Figure S3).

\section{DISCUSSION}

The present meta-analysis showed that SGLT2 inhibitors were not significantly associated with increased risk of melanoma among the patients with T2D. However, we cannot rule out the potential for harm. A non-significant decrease in risk of NMSC associated with SGLT2 inhibitors was observed, while a significantly decreased risk was detected among trials with duration $<52$ weeks. There was zero, low, and moderate heterogeneity in the meta-analyses. No evidence of potential publication bias was observed.

Evidence drawn from available RCTs did not suggest a significantly increased risk of melanoma associated with SGLT2 inhibitors (mainly empagliflozin), which was in line with the European Medicines Agency Assessment Report ${ }^{8}$ as well as a pooled analysis of 15 trials (four melanoma cases with $10 \mathrm{mg}$ empagliflozin versus two cases with placebo). ${ }^{14}$ Of note, a slightly low incidence of melanoma was observed in the 
dapagliflozin group $(2 / 2,691)$ versus in the control group $(1 / 1,936)$ in our meta-analysis. Given unknown biological mechanisms linking SGLT2 inhibition to melanocytic carcinogenesis, it is difficult to determine whether the possibly high melanoma risk is attributable to empagliflozin use or is simply the result of chance. ${ }^{9}$ Furthermore, the opposite trend was observed for risk of NMSC, indicating that SGLT2 inhibitors may not be photosensitizers that increase melanoma risk through phototoxicity. We observed a significantly decreased risk of NMSC in the trials with follow-up $<52$ weeks but not among those with duration $\geq 52$ weeks, which might be driven by small number of events (1/1913 in SGLT2 inhibitor group versus 6/661 in control group) or possibly due to an imbalance in frequency of pre-existing NMSC cases between groups at baseline. Therefore, based on current evidence, we were unable to rule out the potential risk of melanoma associated with SGLT2 inhibitors, and determine whether a beneficial role of SGLT2 inhibitors against NMSC may exist. Ongoing long-term post-marketing surveillance is needed to keep monitoring the risk of melanoma and NMSC among patients taking SGLT2 inhibitors.

We acknowledged that our study had several limitations. First, our estimates may be subject to reporting bias because skin cancers were not specified end points in these trials which would result in less reports of skin cancers. In addition, only trials reporting the outcomes of skin cancer were considered in this meta-analysis. Second, our results should be interpreted with caution because of the small number of skin cancer cases and 
short term of follow-up of included trials (median: 52 weeks). Our findings, especially in subgroup analyses, need to be further assessed by future long-term studies.

Noteworthily, no prospective observational study has examined the association of SGLT2 inhibitors and risk of skin cancer yet. Therefore, we could not conduct the meta-analysis based on observational data.

In conclusion, current evidence from randomized trials did not find a significantly increased risk of skin cancer among patients taking SGLT2 inhibitors. However, the potential melanoma risk by SGLT2 inhibitors cannot be ruled out and should be further monitored in future large prospective observational studies and post-marketing surveillance. 


\section{Conflict of interest}

None declared

\section{Author contributions}

H.T. and J.H. had the idea for the study and led the study design. H.T. and K.Y. identified and selected trials and extracted data. H.T. performed all data analyses, checked for statistical consistency, and interpreted the results. H.T., K.Y., Y.S., and J.H. contributed to data interpretation. H.T. drafted the report, and all other authors (K.Y., Y.S., and J.H.) critically reviewed the report. J.H. is the guarantor of this work and, as such, had full access to all the data in the study and takes responsibility for the integrity of the data and the accuracy of the data analysis. 


\section{References}

1. Chen LH, Leung PS. Inhibition of the sodium glucose co-transporter-2: its beneficial action and potential combination therapy for type 2 diabetes mellitus. Diabetes Obes Metab. 2013; 15: 392-402.

2. Wanner C, Inzucchi SE, Lachin JM, et al. Empagliflozin and progression of kidney disease in type 2 diabetes. N Engl J Med. 2016; 375: 323-334.

3. Zinman B, Wanner C, Lachin JM, et al. Empagliflozin, cardiovascular outcomes, and mortality in type 2 diabetes. N Engl J Med. 2015; 373: 2117-2128.

4. Neal B, Perkovic V, Mahaffey KW, et al. Canagliflozin and Cardiovascular and Renal Events in Type 2 Diabetes. N Engl J Med. 2017; 377: 644-657.

5. Zaccardi F, Webb DR, Htike ZZ, Youssef D, Khunti K, Davies MJ. Efficacy and safety of sodium-glucose co-transporter-2 inhibitors in type 2 diabetes mellitus: systematic review and network meta-analysis. Diabetes Obes Metab. 2016; 18: 783-794.

6. Fralick M, Schneeweiss S, Patorno E. Risk of Diabetic Ketoacidosis after Initiation of an SGLT2 Inhibitor. N Engl J Med. 2017; 376: 2300-2302.

7. Li D, Yang JY, Wang T, Shen S, Tang H. Risks of diabetic foot syndrome and amputation associated with sodium glucose co-transporter 2 inhibitors: A Meta-analysis of Randomized Controlled Trials. Diabetes Metab. 2018 Feb 13. pii: S1262-3636(18)30041-7. doi: 10.1016/j.diabet.2018.02.001. [Epub ahead of print] 8. European Medicines Agency. Assessment Report: Jardiance (empagliflozin). 
http://www.ema.europa.eu/docs/en GB/document library/EPAR - Public assessment report/human/002677/WC500168594.pdf, on page 85. Accessed May 9, 2018.

9. US Food and Drug Administration. FDA briefing document: Endocrine and Metabolic Drug Advisory Committee meeting.

https://www.fda.gov/downloads/AdvisoryCommittees/UCM508422.pdf, on page 8. Accessed May 9,2018.

10. Higgins JP, Altman DG, Gotzsche PC, et al. The Cochrane Collaboration's tool for assessing risk of bias in randomised trials. BMJ. 2011; 343: d5928.

11. Brockhaus AC, Bender R, Skipka G. The Peto odds ratio viewed as a new effect measure. Stat Med. 2014; 33: 4861-4874.

12. Higgins JP, Thompson SG, Deeks JJ, Altman DG. Measuring inconsistency in meta-analyses. BMJ. 2003; 327: 557-560.

13. Deeks JJ, Higgins JPT, Altman DG. Analysing data and undertaking meta-analysis. In: Higgins JPT, Green S, eds. Cochrane handbook for systematic reviews of interventions, Version 510: The Cochrane Collaboration, 2011

14. Kohler S, Zeller C, Iliev H, Kaspers S. Safety and Tolerability of Empagliflozin in Patients with Type 2 Diabetes: Pooled Analysis of Phase I-III Clinical Trials. Adv Ther. 2017; 34: 1707-1726. 
Table 1. Subgroup and univariable meta-regression analyses of the association between SGLT2 inhibitors and risk of melanoma and non-melanoma skin cancer in patients with type 2 diabetes.

\begin{tabular}{|c|c|c|c|c|c|c|c|c|c|c|c|c|}
\hline \multirow[b]{2}{*}{$\begin{array}{l}\text { Subgroup } \\
\text { analyses }\end{array}$} & \multirow[b]{2}{*}{$\begin{array}{l}\text { No. of } \\
\text { trials }\end{array}$} & \multirow{2}{*}{$\begin{array}{l}\text { No. of } \\
\text { patients } \\
\text { (S/C) }\end{array}$} & \multicolumn{5}{|c|}{ Melanoma } & \multicolumn{5}{|c|}{ Non-melanoma skin cancer } \\
\hline & & & $\begin{array}{l}\text { No. of } \\
\text { events } \\
(\mathrm{S} / \mathrm{C})\end{array}$ & $\begin{array}{l}\text { Peto odds ratio } \\
(95 \% \mathrm{Cl})\end{array}$ & $\begin{array}{l}\text { Het } \\
\left(I^{2}, \%\right. \\
)\end{array}$ & $\begin{array}{l}p- \\
\text { value } \\
t\end{array}$ & $\begin{array}{l}p- \\
\text { value }^{\ddagger}\end{array}$ & $\begin{array}{l}\text { No. of } \\
\text { events } \\
\text { (S/C) }\end{array}$ & $\begin{array}{l}\text { Peto odds ratio } \\
(95 \% \mathrm{Cl})\end{array}$ & $\begin{array}{l}\text { Het } \\
\left(I^{2}, \%\right. \\
)\end{array}$ & $\begin{array}{l}p- \\
\text { value } \\
t\end{array}$ & $\begin{array}{l}p- \\
\text { value }^{\ddagger}\end{array}$ \\
\hline \multicolumn{13}{|c|}{ Subgroup by type of SGLT2 inhibitor } \\
\hline Empagliflozin & 11 & $9172 / 4964$ & $12 / 2$ & $\begin{array}{l}2.64 \\
(0.88,7.93)\end{array}$ & 0 & \multirow[t]{5}{*}{0.20} & \multirow[t]{5}{*}{0.45} & $50 / 35$ & $\begin{array}{l}0.75 \\
(0.48,1.18)\end{array}$ & 0 & \multirow[t]{5}{*}{0.86} & \multirow[t]{5}{*}{0.68} \\
\hline Dapagliflozin & 7 & $2691 / 1936$ & $2 / 1$ & $\begin{array}{l}0.38 \\
(0.02,7.00)\end{array}$ & 42.3 & & & $4 / 8$ & $\begin{array}{l}0.44 \\
(0.14,1.38)\end{array}$ & 12.7 & & \\
\hline Canagliflozin & 1 & $477 / 237$ & $0 / 0$ & NA & NA & & & $1 / 0$ & $\begin{array}{l}4.47 \\
(0.07,286.85)\end{array}$ & NA & & \\
\hline Ertugliflozin & 1 & $313 / 154$ & $1 / 0$ & $\begin{array}{l}4.45 \\
(0.07,287.44)\end{array}$ & NA & & & $1 / 1$ & $\begin{array}{l}0.46 \\
(0.02,8.84)\end{array}$ & NA & & \\
\hline Ipragliflozin & 1 & $291 / 73$ & $0 / 0$ & NA & NA & & & $0 / 0$ & NA & NA & & \\
\hline \multicolumn{13}{|c|}{ Subgroup by type of control } \\
\hline Placebo & 17 & $11222 / 5686$ & $13 / 3$ & $\begin{array}{l}1.80 \\
(0.62,5.25)\end{array}$ & 0 & \multirow[t]{2}{*}{0.29} & \multirow[t]{2}{*}{0.34} & $52 / 37$ & $\begin{array}{l}0.74 \\
(0.47,1.15)\end{array}$ & 0.2 & \multirow[t]{2}{*}{0.55} & \multirow[t]{2}{*}{0.58} \\
\hline $\begin{array}{l}\text { Other active } \\
\text { drugs }\end{array}$ & 5 & $2170 / 1678$ & $2 / 0$ & $\begin{array}{l}7.55 \\
(0.47,120.75)\end{array}$ & NA & & & $4 / 7$ & $\begin{array}{l}0.51 \\
(0.15,1.69)\end{array}$ & 0 & & \\
\hline \multicolumn{13}{|c|}{ Subgroup by mean or median age of patients } \\
\hline$<60$ years & 15 & $5971 / 3079$ & $6 / 1$ & $\begin{array}{l}2.42 \\
(0.46,12.74)\end{array}$ & 2.4 & \multirow[t]{2}{*}{1.0} & \multirow[t]{2}{*}{0.87} & $9 / 14$ & $\begin{array}{l}0.43 \\
(0.18,1.01)\end{array}$ & 0 & \multirow[t]{2}{*}{0.16} & \multirow[t]{2}{*}{0.18} \\
\hline$\geq 60$ years & 6 & $6973 / 4285$ & $9 / 2$ & $\begin{array}{l}2.04 \\
(0.59,7.12)\end{array}$ & 0 & & & $47 / 30$ & $\begin{array}{l}0.82 \\
(0.51,1.32)\end{array}$ & 0 & & \\
\hline \multicolumn{13}{|c|}{ Subgroup by race/ethnicity } \\
\hline White & 16 & $11132 / 6305$ & $15 / 3$ & $\begin{array}{l}2.17 \\
(0.80,5.89)\end{array}$ & 0 & NA & NA & $55 / 43$ & $\begin{array}{l}0.71 \\
(0.47,1.08)\end{array}$ & 0 & 0.75 & 0.79 \\
\hline
\end{tabular}

This article is protected by copyright. All rights reserved. 


\begin{tabular}{|l|l|l|l|l|l|l|l|l|l|l|l|l|}
\hline Asian & 5 & $1812 / 1059$ & $0 / 0$ & NA & NA & & & $1 / 1$ & $\begin{array}{l}0.46 \\
(0.02,8.80)\end{array}$ & 56.4 & \\
\hline Subgroup by trial duration
\end{tabular}

${ }^{\dagger} p$-value for potential effect modification by each stratified factor on the pooled effect size estimate based on meta-regression models.

${ }_{\mathrm{f}} \mathrm{p}$-value for interactions assessed with Cochran's Q-test.

Abbreviations: Het, heterogeneity; SGLT2 inhibitor, sodium-glucose co-transporter 2 inhibitor; Cl, confidence interval; S/C, SGLT2 inhibitors group/control group; NA, not applicable. 


\section{Figure Legends:}

Figure 1. Meta-analysis of the association between SGLT2 inhibitors and risk of melanoma and non-melanoma skin cancer in patients with type 2 diabetes. 
Figure 1

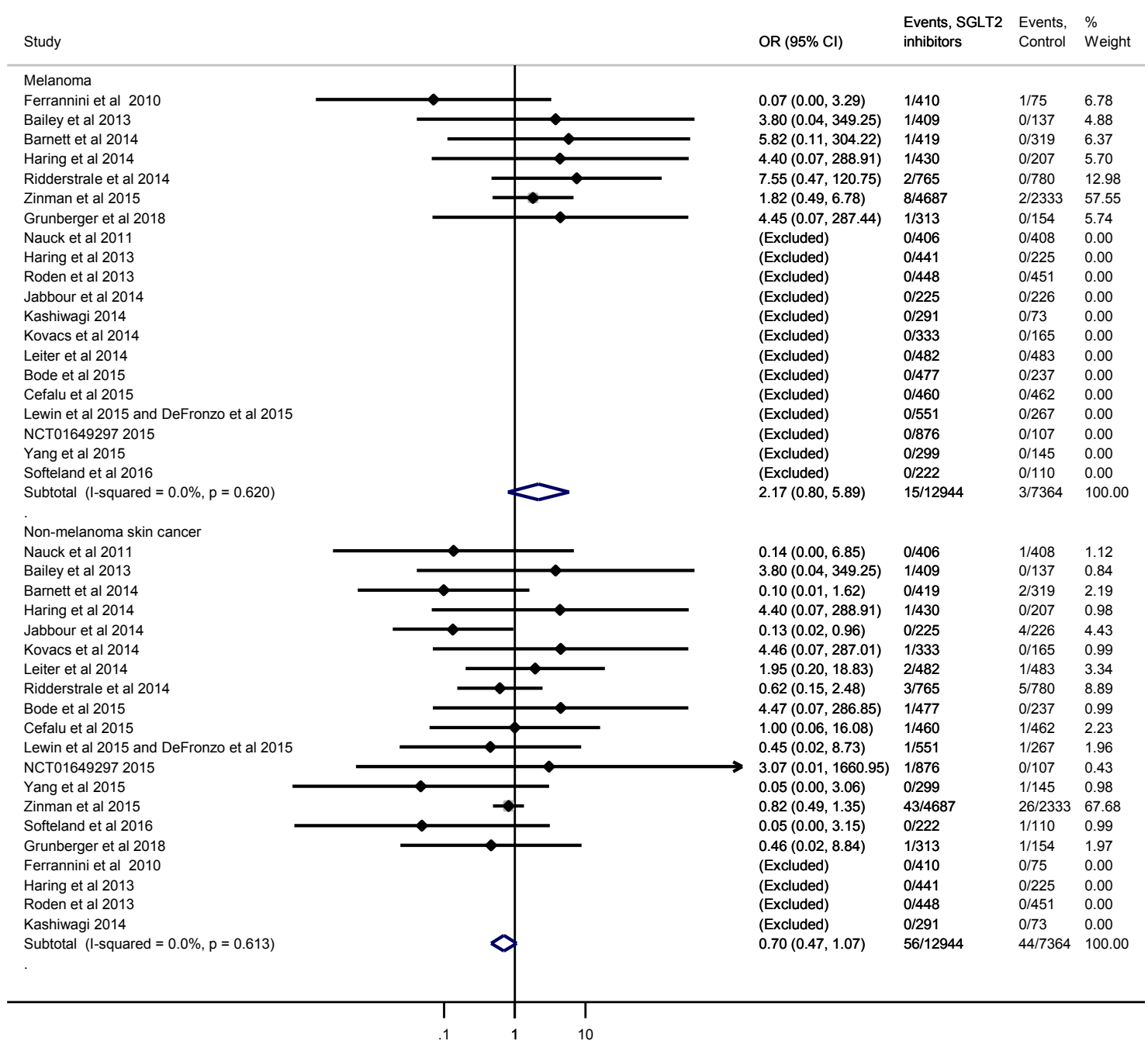

